\title{
Adolescent Sexual Victimization, ADHD Symptoms, and Risky Sexual Behavior
}

By: Jacquelyn W. White and Cheryl Buehler

White, J.W. \& Buehler, C. (2012). Adolescent sexual victimization, ADHD symptoms, and risky sexual behavior. Journal of Family Violence. (published online Jan 31, 2012). doi:10.1007/s10896-012-9411-y.

***Note: This version of the document is not the copy of record. Made available courtesy of Springer Verlag. Link to Full Text:

http://www.springerlink.com/content/m73788234r273712/

\begin{abstract}
:
This study examined the association between ADHD symptoms experienced before age 12 and sexual victimization during adolescence in a sample of 374 college women who had not been sexually victimized as children. The linkage with risky sexual behavior and the moderating effects of sociodemographic factors also were considered using structural equation modeling. ADHD symptoms were associated with greater sexual victimization during adolescence and were linked with sexual victimization through engagement in risky sexual behavior.

Sociodemographic factors did not affect the overall model; however, sociodemographic factors were differentially related to certain paths in the model. In particular, the associations between ADHD symptoms and sexual victimization, as well as risky sexual behavior, were stronger for Black than White women. Also, the relation between ADHD risky sexual behaviors was stronger for young women who grew up with only their mother than with both parents, and for those whose primary caregiver was employed rather than unemployed.
\end{abstract}

Article:

Sexual victimization is a serious problem affecting young women in high school and college. It can take many forms, ranging from being the target of unwanted sexual contact, to verbal pressure for sex, to experiences that meet the legal definitions of rape and attempted rape (Koss et al. 2007). Humphrey and White (2000) found that $50 \%$ of their sample of college women reported some form of sexual victimization during adolescence alone, with $20.4 \%$ experiencing at least one rape or attempted rape. More recent studies have also confirmed high rates of sexual victimization in adolescence (Halpern et al. 2009; Young and Furman 2009). Although reviews of the literature identify vulnerability factors at all levels of a young woman's social ecology (Ullman and Najdowski 2011), prior victimization history has received greater attention than other factors.

Researchers have suggested that various forms of child abuse, including sexual, physical and psychological abuse have long-lasting adverse consequences, in part due to disruption in brain development. Such disruption has been identified as one mechanism that impacts emotional and cognitive functioning by disrupting multiple biological regulatory systems that may interfere with recognition of danger via hyperarousal, emotional dysregulation, and impaired executive functioning (Gidycz et al. 2006; Hedtke et al. 2008; Watts-English et al. 2006). Although the present study is not examining disruptions in biological regulatory systems, these findings 
provide the foundation for theoretical consideration of factors other than childhood abuse that are related to these developmental difficulties that might result in increased risk for adolescent sexual victimization. Given that substantial numbers of young women who are sexually victimized in adolescence have not been sexually victimized in childhood (63\% in Halpern et al. 2009; 45\% in Smith et al. 2003), an interesting and important question arises. Are there biobehavioral risk factors related to cognitive and emotional mechanisms that might disrupt the ability to recognize and/or respond to danger?

One potentially important biobehavioral risk factor is attention deficit/hyperactivity disorder (ADHD). The Diagnostic and Statistical Manual of Mental Disorders (DSM-IV-TR; American Psychiatric Association 2000) defines ADHD as "a persistent pattern of inattention and/or hyperactivity-impulsivity that is more frequently displayed and severe than is typically observed in individuals at a comparable level of development” (p. 85). This disorder includes three categories of symptoms: inattention (e.g., easily distracted, difficulty completing tasks), hyperactivity (e.g., excessive talking, difficulty engaging in quiet activities), and impulsivity (e.g., impatience, difficulty delaying gratification).

The symptoms associated with ADHD might be good candidates as risk factors for sexual victimization during adolescence. In reviewing literature on ADHD, Quinn (2008 cited in Waite 2010) recommends that because ADHD, as a diagnostic category, is often missed in girls and female adolescents, it is better to focus on assessing symptoms than rely on a clinical diagnosis of ADHD. Waite (2007) details several of the functional impairments that young women with ADHD symptoms may experience, including “(a) diminished self-image and self-esteem; (b) less-developed or underdeveloped interpersonal sensitivity skills and awareness of relationship dynamics; (c) decreased information processing skills, such as the ability to retain important information and filter out what is unnecessary; (d) inability to plan and organize effectively without feeling overwhelmed; and (e) increased emotional reactivity” (p. 185). These impairments noted by Waite are similar to outcomes associated with childhood sexual abuse (Chu et al. 2011) and to predictors of future sexual victimization (Ullman and Najdowski 2011; Vicary et al. 1995).

The effects of ADHD symptoms during childhood on adolescent sexual victimization may be the result of impaired regulatory behavioral systems (Winters et al. 2009). These impaired systems may interfere with a young woman's ability to assess and evaluate situations holding risk for sexual assault. A number of scholars have invoked appraisal models to account for women's inability to always successfully handle risky situations (Nurius and Norris 1995). This is not intended to hold women blameworthy; rather, until male sexual perpetration is eliminated, the burden for deterring an assault too often falls on women (Lonsway 1996). Symptoms of ADHD may alter a women's ability to assess danger cues and to choose and execute appropriate actions to diffuse or escape the situation.

The present study offers a novel contribution by examining ADHD symptoms as a risk factor for adolescent sexual victimization in girls who were not sexually victimized in childhood. We focus on this large subset of adolescents because much less is known about sexual victimization in this relatively substantial population of adolescents, and because we wanted to minimize time 
ordering problems that would arise for those female youth who experienced ADHD symptoms following sexual victimization during early childhood (Briscoe-Smith and Hinshaw 2006).

The present study also makes an important contribution to the literature by examining the role of risky sexual behavior in linking ADHD symptoms to adolescent sexual victimization.

Theoretically, this linkage is consistent with Repetti et al.'s (2002) conceptual model in which biobehavioral vulnerabilities that affect emotional and cognitive regulation (ADHD symptoms in the present study) influence risky behavior over time. Empirically, several studies among adolescents (Monuteaux et al. 2007) and adults (Flory et al. 2006; Winters et al. 2009) have found an association between ADHD symptoms and sexual risk-taking. Furthermore, risky sexual behavior is a known risk factor for sexual victimization (Fargo 2009).

\section{MODERATING ROLE OF SOCIODEMOGRAPHIC FACTORS}

Steinberg et al. (2006) have argued that context affects brain development, in particular, those processes of impulsivity and inattention often associated with ADHD symptoms that we are focused on in the present study. Specifically, various facets of a stressful childhood, often indexed by socioeconomic status, primary parent employment status, family structure, and race, can result in changed neurobiological systems, and ultimately contribute to an increased likelihood of engaging in risky behaviors during adolescence (Steinberg 2010). Other scholars have argued that poverty, often a marker of a stressful childhood, takes a toll on the developing child's ability to self-regulate (Evans and Rosenbaum 2008; Marcovitch et al. 2010). In addition, several studies have found that, when controlling for social class, race and ethnicity are associated with ADHD symptoms, with Blacks and Hispanics manifesting higher prevalence rates (Cuffe et al. 2005). Rydell (2010) found, in addition to ethnicity, family structure was associated with ADHD symptoms. In the current study, we examined the moderating effects of four sociodemographic factors (socioeconomic status, primary caregiver employment status, race, family structure). Previous research has shown an association between each of these factors and sexual victimization, as well as with risky sexual behavior.

With regard to predicting sexual victimization, data from the National Crime Victimization Survey (Slashinski et al. 2003; Tjaden and Thoennes 2000) indicate that younger, ethnic minority (specifically, Native American and Black), unmarried or separated women are more likely to be sexually victimized than other women. We extended this literature and tested Steinberg et al.'s (2006) theoretical ideas regarding context by examining these sociodemographic factors as exacerbating moderators of the effects of ADHD symptoms on female adolescent's sexual victimization.

With regard to risky sexual behavior, empirical evidence indicates that large numbers of young people are engaging in early and/or risky sexual behaviors with a myriad of negative consequences (U.S. Department of Health and Human Services 2000). Components of youths' social ecology repeatedly identified as key risk factors of risky sexual behaviors include: socioeconomic status, family structure, and race/ethnicity (Crockett et al. 2003; Fergus et al. 2009; Metzler et al. 1994; Roosa et al. 1997). Family environment is central to understanding risky sexual behavior because "risky family characteristics create a cascade of risk" (p. 330) that is associated with multiple deleterious outcomes for youth (Repetti et al. 2002; Whitbeck et al. 2001). We extended these findings by examining the moderating effects of socioeconomic status, 
race, and family structure as potential amplifiers of the effects of ADHD symptoms on risky sexual behavior.

Several researchers have suggested it is neither the presence nor absence of a specific risk factor that increases the likelihood of an adverse outcome; rather, it is the accumulation of risk (Flouri and Kallis 2011; Repetti et al. 2002; Steinberg et al. 2006). Therefore, we also created a cumulative risk index comprised of a sum of the four background factors to further address the role of contextual factors.

In sum, we hypothesized that, among young women who had not been sexually abused during childhood, ADHD symptoms experienced prior to age 12 would be positively associated with female adolescents' sexual victimization. We also hypothesized that risky sexual relationships would link ADHD symptoms and sexual victimization. Finally, we hypothesized that the proposed model would be stronger in the presence of socioeconomic risk factors such that family socioeconomic status during childhood, primary caregiver's employment status, race, and childhood family structure moderate the hypothesized direct and linking associations.

\section{METHOD}

\section{Participants}

A sample of 417 college women from a medium-sized southeastern state university was recruited through introductory psychology classes and received course credit in exchange for participation. In the present sample, $92.7 \%$ were freshmen or sophomores, with a mean age of 18.9 years $(S D=2.9)$. Students signed up for the study, designed specifically for females, through an online system that provided a general title and number of credits to be earned. Upon arrival at the study, women were told the survey was about "childhood experiences, parental support, rate of physical maturation, and attitudes about dating and sexual behavior.... [and that] results should contribute to a growing understanding of various factors related to adolescent sexual behavior;" they were further informed that the only risk may come from "being asked questions about explicit sexual behaviors." No students withdrew at the consent phase of the study; hence, it is unlikely that self-selection influenced the results on sexual victimization and other specific study variables.

From this group of participants, we selected a subsample of young women who did not report any childhood sexual abuse $(n=374$ for no abuse before age $13,89.7 \% ; n=43$ for childhood sexual abuse, $10.3 \%$ ). Of the subsample, $71.9 \%$ were non-Hispanic, White; $20.3 \%$ Black; $2.1 \%$ Hispanic; 3.7\% Asian; and 1.9\% other. With regard to childhood socioeconomic status, $15.2 \%$ were low to low-middle class; 51.9\% middle class; 29.5\% upper-middle class; and 3.5\% upper class. With regard to primary caregiver employment, $91.7 \%$ reported continuous employment; 5.3\% variable employment; and 2.9\% never employed. Finally, 75.4\% lived with both parents; $20.6 \%$, with mother only; $2.4 \%$ with father only; $1.1 \%$ with relatives; and .5\% with unrelated adults.

\section{Data Collection Procedures}

Following receipt of approval from the university's Institutional Review Board, undergraduate female research assistants administered a survey in 1-hr small group sessions. Surveys were presented in scantron form and computerized data files were created from the scantrons. Informed consent was obtained, and complete confidentiality of the participants was protected by using randomly determined ID numbers and by not including names in the data set. 


\section{Measurement}

Attention Deficit/Hyperactivity Disorder (ADHD) Symptomology: Students were asked to rate the extent to which they experienced 18 different symptoms before the age of 12 using the DuPaul et al. (1998) modification of Barkley and Murphy’s (1998) rating scale (modification focused the assessment on self-reported symptoms before age 12). Sample items included symptoms of inattention, such as "difficulty sustaining attention in tasks or fun activities," and symptoms of hyperactivity, such as "feel on the go or driven by a motor." The item response format ranged from 1 (never or rarely) to 4 (very often), and a summed total score was created, resulting in scores ranging from 12 to $48(\alpha=.92)$.

Risky Sexual Behaviors (RSB): RSB's were defined as six behaviors that encompassed casual sexual relationships (i.e., partners with unknown sexual histories; items were taken from Noll et al. 2003 and Soet et al. 1999). The item response format ranged from 1 (never) to 5 (always) and $\alpha=.85$. Items were averaged to retain the never to always connotation, thus scores ranged from 1 to 5 .

Female Adolescent Sexual Victimization: Respondents were asked to indicate how many times they had experienced each of the several non-consensual sexual behaviors using a modified version of the Koss et al. (1987) Sexual Experiences Survey (Kosson et al. 1997). The modification permitted the assessment of 24 different types of experiences: 6 tactics (i.e., perpetrator used verbal pressure, used authority, threatened to hurt, used physical force, gave alcohol or drugs, took advantage of self-induced intoxication) $\times 4$ outcomes (i.e., unwanted contact, attempted intercourse, completed intercourse, other sex acts). Responses could range from zero to a number indicated by the respondent. Because the instrument is reflective of an induced rather than latent model, measuring internal consistency is inappropriate (Koss et al. 2007). Respondents also indicated the age at which each experience first happened. Any respondent who indicated that they had at least one of the experiences before the age of 13 was designated a childhood sexual assault victim and was not included in the subsample for this study $(n=43,10.3 \%)$. Types of childhood sexual victimization included: unwanted contact (53.5\%), verbally coerced sexual intercourse (11.6\%), attempted rape (11.6\%), and rape, (23.3\%). The total number of coercive sexual experiences after the age of 12 was summed across the 24 experiences. Actual scores ranged from zero (56.8\% of the sample) to 953 (mean $=18.2$, with $67 \%$ reporting fewer than 11). Classifying victims as a function of the most extreme experience they had (based on Koss et al. 2007) revealed that $25.7 \%$ of the victims experienced unwanted contact, 9.3\%, verbally coerced sexual intercourse, $27.9 \%$, attempted rape, and 37.1\%, rape. These numbers are consistent with what previous researchers typically report, although lower for verbal coercion (Testa et al. 2004, which had an older sample).

Demographic Variables (Moderators): All of the demographic variables were measured using youth responses to a background questionnaire constructed for the larger study. Family socioeconomic status was measured using a single-item question that asked about the family's socioeconomic status (SES) while growing up (prior to age 12) and was answered using five response options: 1 = low SES; 2 = low to middle SES; 3 = middle SES; 4 = middle to upper SES; 5 = upper SES. For the present study, a dummy code was created to distinguish lower SES 
(0 = low SES, low to middle SES) from higher SES (1 = middle SES, middle to upper SES, and upper SES). Subjective rather than objective SES was assessed because of evidence of its relation to objective SES and superior prediction of various health outcomes (Adler et al. 2000).

Primary caregiver's employment (prior to age 12) was measured using a single-item question that asked about the primary caregiver's employment status and was answered using three response options: 1 = always employed; 2 = he or she worked on and off; $3=$ never employed. A dummy code was created to distinguish less employment $(0=$ never employed, he or she worked on and off) from continuous employment ( 1 = always employed). Race was measured using a single-item question that asked about race or ethnic group and was answered using five response options: 1 = African American or Black; 2 = Hispanic or Latin American or Mexican American; $3=$ White, non-Hispanic; $4=$ Asian; and $5=$ Other. Moderating analyses for race included only Black and White, non-Hispanic women to facilitate interpretations of any found differences. Sample sizes for Hispanic and Asian women were too small for specialized analyses.

Family structure was measured using a single-item question that asked for the woman's primary living circumstances prior to the age of 12 using eight response options: 1 = parental home (both parents); 2 = parental home (mother only); $3=$ parental home (father only); $4=$ relatives (other than parents); 5 = with unrelated adults; $6=$ foster home; $7=$ group home; $8=$ institution. Moderating analyses for family structure in this study included only women who lived with either both parents or with only their mother. Sample sizes for other family structures (e.g., father only, unrelated adult, foster home) were too small for specialized analyses.

\section{Data Analysis Procedures}

Data were analyzed using SPSS 18 (IBM 2011) for descriptive analyses and AMOS 20 (Arbuckle 2011) for structural equation modeling. Structural equation modeling (SEM) was a good statistical procedure for this study because it parsimoniously tests for mediating pathways and accommodates well to testing for moderating patterns for pathways (Byrne 2001). Manifest variables, rather than latent variables, were used in the path models because multiple measures of each construct were not available and because SEM can easily accommodate manifest variables. Unless otherwise noted, the sample size for each analysis was 374 young women. There was very little missing data (less than 2\%). SEM adjusts for missing values using full information maximum likelihood estimations (FIML), which is a strong technique that minimizes biased estimates (Acock 2005).

\section{RESULTS}

There was adequate variability on ADHD symptoms with a range from 16 to 69. The mean value was 30.05 ( $S D=9.49$ ). Although the present analyses just focused on young women who had not reported any childhood sexual victimization, it is important to note the level of childhood ADHD symptoms reported by women with childhood sexual victimization $(M=33.7 ; S D=11.4)$ was not statistically different from women with only adolescent sexual victimization experiences $(M=30.2 ; S D=10.2)$, and both were significantly greater than those with no sexual victimization experiences $(M=28.5 ; \mathrm{SD}=8.0), F(2,370)=11.07 p<.001$, followed by Bonferonni post hoc comparisons. 
There was also variability on female adolescents' sexual victimization. Thirty-eight percent of the young women had experienced as least some victimization and there was tremendous variability on frequency and severity among those women who had been victimized (range = 157). Classifying victims as a function of the most extreme experience they had (based on Koss et al. 2007) revealed that $25.7 \%$ of the victims experienced unwanted contact (mean number of all experiences $=3.3$ ), 9.3\% verbally coerced sexual intercourse (mean number of all experiences $=$ 4.9), 27.9\% attempted rape (mean number of all experiences $=8.1$ ), and 37.1\% rape (mean number of all experiences $=16.5$ ). The total number of victimization experiences was highly associated with the most severe experience, $F(3,139)=7.0, p<.001$; that is, women with more severe experiences also had more total victimization experiences of all types. Using a continuous variable more adequately captures this than would a dichotomous variable that only distinguished victimized from not victimized.

In addition, there was adequate variability on the risky sexual relationships variable, with $64.7 \%$ of the young women having reported at least some risk taking during adolescence. The mean indicated, however, that sexual risk taking was a low base-rate behavior among this group of young women. As expected, there were statistically significant positive correlations among ADHD symptoms, risky sexual relationships, and female adolescent's sexual victimization. Additionally, socioeconomic status was positively correlated with race and family structure. Race and family structure also were positively correlated. Correlations among the background variables were modest in strength (see Table 1).

Table 1 Summary of zero-order correlations, means, and standard deviations

\begin{tabular}{|c|c|c|c|c|c|c|c|}
\hline & 1 & 2 & 3 & 4 & 5 & 6 & 7 \\
\hline 1. ADHD symptoms & - & & & & & & \\
\hline 2. Risky sexual relationships & .19 & - & & & & & \\
\hline 3. Sexual victimization & .20 & .24 & - & & & & \\
\hline 4. Socioeconomic status ${ }^{a}$ & .11 & .04 & .02 & - & & & \\
\hline 5. Parent employment ${ }^{\mathrm{a}}$ & .04 & .11 & -.07 & .09 & - & & \\
\hline 6. Race $^{\mathrm{a}}$ & .22 & -.12 & -.02 & .12 & -.03 & - & \\
\hline 7. Family structure ${ }^{a}$ & .09 & -.11 & .00 & .24 & .01 & .27 & - \\
\hline Mean & 30.05 & 1.56 & 3.43 & .85 & .92 & .78 & .79 \\
\hline$S D$ & 9.49 & .68 & 8.24 & .36 & .28 & .42 & .41 \\
\hline Range & $16-69$ & $1-3.67$ & $1-57$ & $0-1$ & $0-1$ & $0-1$ & $0-1$ \\
\hline
\end{tabular}

\section{Model Testing: Direct and Mediating Associations}

The first hypothesis was that, among young women who had not been sexually abused during childhood, ADHD symptoms experienced prior to age 12 would be associated positively with female adolescent's sexual victimization. Using SEM, the standardized regression coefficient was .20 $(p<.001)$. Fit statistics were not estimated because the model was fully saturated. 
The second hypothesis was that risky sexual relationships would link ADHD symptoms and sexual victimization. This hypothesis was supported (see Fig. 1). There was a significant pathway from ADHD symptoms to sexual victimization through risky sexual relationships (Sobel $t=2.67, p=.007$ ). A mediating function (rather than a linking function), was not demonstrated because the direct association between ADHD symptoms and victimization remained statistically significant and declined little in magnitude (i.e., dropped from $\beta=.20$ to $\beta=.16$ ). As such, the results from this study indicate two possible roles for ADHD symptoms: a direct association with female adolescents' sexual victimization and an indirect association with victimization through risky sexual relationships.

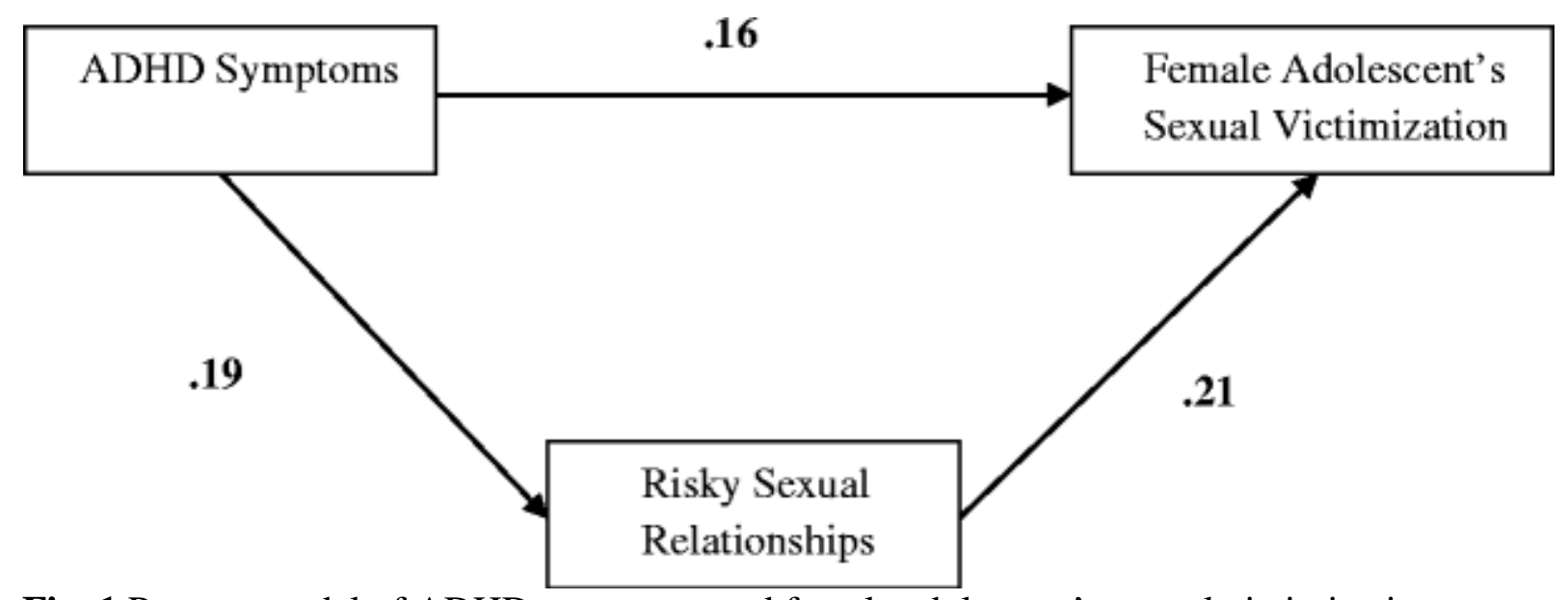

Fig. 1 Process model of ADHD symptoms and female adolescent's sexual victimization

\section{Does the Same Model Fit All? The Moderating Effects of Sociodemographic Factors}

The moderating effects of family socioeconomic status (primary caregiver's employment status, childhood family structure, and race) were each examined in separate multiple-group SEM models. The mediating model was compared across the two groups for a given moderator (e.g., lower and higher SES) by first estimating a fully constrained model that set the three paths to be equal across groups. A second analysis was then done in which the three paths were allowed to vary across the two groups. The chi-squares from the two analyses were compared using a chisquare difference test. Significant chi-square difference tests were probed for specific path differences across groups by using the critical ratio (C.R.) values that distribute as a $z$ score.

Childhood Family Socioeconomic Status: SES was not a significant moderator. The mediating model did not differ for young women who grew up in families with lower SES and young women who grew up in families with higher SES $\left(\Delta \chi^{2}=.91, d f=3, p=.82\right)$. As such, the deleterious potential effects of ADHD symptoms for female sexual victimization characterize young women with a variety of backgrounds in terms of parents' socioeconomic status.

Primary Caregiver Employment Status: Primary parent's employment status was a significant moderating factor $\left(\Delta \chi^{2}=8.49, d f=3, p=.037\right)$. The positive association between ADHD symptoms and risky sexual relationships was statistically significant only when the primary caregiver was always employed (C.R. $=2.54, p<.05 ; \beta=.19, p<.001)$. There was no association 
when employment was variable or the caregiver was not employed $(\beta=.05, n s)$. There were no employment group differences for the other two paths.

Childhood Family Structure: This analysis included only female youth who lived with both parents or only their mothers during childhood; the sample size was reduced slightly for this analysis (i.e., 367 rather than 374). Using rigorous criteria of a significant statistical omnibus test (the chi-square difference test in this case), family structure was not a significant moderator. The mediating model as a whole did not differ for young women who grew up living only with their mothers and young women who grew up living with both parents $\left(\Delta \chi^{2}=4.79, d f=3, p=.19\right)$. Examining the three C.R'.s, however, there was one significant group difference (C.R. $=2.13$, $p<.05)$. The positive association between ADHD symptoms and risky sexual relationships was stronger for youth who lived only with mother $(\beta=.26, p<.001)$ than for youth who lived with both parents $(\beta=.18, p<.001)$.

Race/Ethnicity: Because this analysis included only Black and White female youth, the sample size was reduced slightly for this analysis (i.e., 345 rather than 374). Race was a significant moderating characteristic $\left(\Delta \chi^{2}=10.83, d f=3, p=.013\right)$. There were no differences across Black and White young women in the positive association between risky sexual relationships and sexual victimization. The two paths involving ADHD as a predictor, however, differed. Controlling for risky sexual relationships, the positive association between ADHD symptoms and adolescent sexual victimization was stronger for Black young women $(\beta=.32, p<.001)$ than for European American young women $(\beta=.14, p<.001)$, although significant for both groups. The positive association between ADHD symptoms and risky sexual relationships also was stronger for Black young women $(\beta=.32, p<.001)$ than for European American young women $(\beta=.21, p<.001)$, though again significant for both groups.

Because race is often confounded with social class, employment status, and family structure (LaVeist et al. 2007), we re-estimated for the moderating effects of race while controlling for the other three background variables. The results did not change (contact corresponding author for statistical details). Thus, ADHD symptoms were a risk factor for women from both racial backgrounds, but evidenced greater vulnerability for Black women.

Cumulative Background Risk: Several researchers have suggested it is not the presence or absence of a specific risk factor that increases the likelihood of an adverse outcome; rather, it is the accumulation of risk (Flouri and Kallis 2011; Repetti et al. 2002). Thus, we also created a cumulative risk index that was a sum of the four background factors. As such, scores could range from 0 (i.e., middle class, primary caregiver always employed, European American, two-parent) to 4 (i.e., lower class, primary caregiver intermittently employed, Black, one-parent). The frequency distribution was $0=55.3 \%, 1=29.7 \%, 2=11 \%, 3=3.5 \%$, and $4=.5 \%$. Given the low percentages for 3 and 4 risk factors, we created a dichotomous cumulative risk moderator in which $85 \%$ of the sample had 0 or 1 background risk factor and $15 \%$ of the sample had 2 through 4 background risk factors. The process model was compared across these two groups of young women. The model tested did not differ across women who had fewer cumulative background risks and those who had two or more $\left(\Delta \chi^{2}=4.10, d f=3, p=.25\right)$. 


\section{DISCUSSION}

The current study provides new information on a previously ignored group of adolescent women-those with no history of childhood sexual victimization. It provides insight into one biobehavioral factor - childhood symptoms of ADHD. We uncovered a positive association between symptoms of ADHD and an increased risk of sexual victimization during adolescence for these young women. This is an important group of adolescent women to study, given the vast majority of young women who were not sexually victimized during childhood.

As described in the introduction, two different literatures have associated, in one set, symptoms of ADHD, and in the other set, childhood sexual abuse, with impairments in self-image, selfesteem, interpersonal sensitivity skills, awareness of relationship dynamics, information processing skills, the ability to plan, and emotional reactivity. By examining ADHD symptoms in adolescent women with no sexual child abuse history we provide an alternative explanation for these impairments and suggest that there may be biobehavioral processes that contribute to increased vulnerability, at least for women without a childhood sexual assault history. The current study suggests that adopting a biobehavioral model of risky sexual behavior and victimization can lead to identifying new groups of women at risk, new hypotheses for further testing, and better intervention and prevention programs for women who need support.

The present findings suggest that in addition to the direct effect of ADHD symptoms, these symptoms may have an indirect effect that operates through risky sexual behavior. Risky sexual behavior has been associated with impaired regulatory systems in earlier research and the present study suggests that this association may help explain the link between risky sexual behavior and the risk of sexual victimization. Our measure of risky sexual behavior encompassed risky relationships, such as having multiple sex partners with unknown sexual histories. This suggests that ADHD symptoms that encompass impulsivity, inattention, and lower delayed gratification may be associated with incautious social interactions with men who have a proclivity toward sexual aggression and willingness to assault vulnerable women. Further research is necessary to determine whether and how subtypes of ADHD (i.e., predominantly inattentive or impulsive or combined) are uniquely relevant to risk-taking.

In the current study, we examined the moderating effects of four sociodemographic factors that shape families' social capital: family socioeconomic status during childhood, primary caregiver's employment status, race, and childhood family structure. Each of these factors is part of young women's developmental/social ecology. We found qualified support for the hypothesis that ADHD symptoms interact with sociodemographic factors in the prediction of risky sexual behavior and sexual victimization during adolescence. Out of 15 possible effects (i.e., 3 paths times 5 moderators including cumulative background risk), one finding suggested complete moderation. The positive association between ADHD symptoms and risky sexual relationships was statistically significant only when the primary caregiver was always employed. However, contrary to our hypotheses, variable or non-employment by the primary caregiver served as a protection factor rather than a risk factor for young women. Because the vast majority of our participants came from two-parent middle-class families (family structure and SES were positively correlated), caregiver availability or presence at various times during the day may have provided a needed safety net. It is possible that the primary care-giver was a stay-at-home parent. As described by Steinberg et al. (2006), such presence may minimize the potentially 
deleterious effects of youths' inattention and impulsivity on emotional and behavior regulation. This is a new finding and will require replication and additional examination to identify the specific aspects of caregiver's employment characteristics that are relevant, including an explication of work hours, schedule, and sources of non-parental care and supervision. There is an abundant literature that supports the protective nature of caregiver availability and supervision during adolescence (e.g., Claes et al. 2005; Fulton and Turner 2008; Murray and Farrington 2010), but in terms of this current moderating finding, additional research is needed to sort through the contributions of specific protective mechanisms such as supervision, emotion coaching by caregivers, and supports for cognitive processing.

There also were two significant partial moderating effects in which a given association was stronger for one group than another and both of these were for the interactions with race. Although the associations were significant for both African and European American young women, the associations involving ADHD as a predictor of both risky sexual behavior and sexual victimization were stronger for Black young women. These moderating effects held when controlling for family SES, caregiver employment status, and family structure. As such, the differences we found in the strength of these associations do not seem to be due to SES, caregiver availability, or number of parents in the household. It also is important to note that the average level of ADHD symptoms was lower for Black young women than for European American young women. Although beyond the scope of the present study, possible explanations for these strength differences may lie in other factors within the social ecology, such as racerelated stressors and community violence (Gibbs 1998). This is a fertile area for future research that will help inform intervention and prevention programs.

We found no moderating effects for 11 of 15 associations, including the analyses that examined the moderating effect of cumulative background risk. Thus, although there was some evidence that specific environmental factors played a unique role in conditionalizing the associations among young women's ADHD symptoms, risky sexual behavior, and sexual victimization, there also was evidence that these associations are relatively robust across a number of contextual factors often associated with risk for adverse outcomes. For example, childhood SES did not contextualize these associations. As such, the positive relations among young women's ADHD symptoms, risky sexual behavior, and sexual victimization characterized women from the different economic and social class conditions represented in the current study. It also is important to note that the positive association between risky sexual behavior and sexual victimization was not moderated by family SES, caregiver employment status, race, family structure, or cumulative risk.

Finally, the present results may have implications for intervention and prevention programs. Programs that identify girls and adolescent women with symptoms of ADHD may want to incorporate activities that assist young women to improve those conditions identified by Waite (2007) that are associated with ADHD, but also increase the risk of sexual victimization, including self-image and self-esteem, interpersonal sensitivity skills, and awareness of relationship dynamics. These programs could assist these young women in improving their ability to retain important information and filter out what is unnecessary and to plan and organize effectively without feeling overwhelmed, especially in situations that hold danger for sexual 
assault. It will be necessary to help young women navigate potentially risky situations until there is more success at reducing young men's proclivity to engage in sexually coercive behaviors.

\section{Limitations}

The present study has a number of limitations including the focus on primarily white, middleclass college students who grew up a two-parent home. Although this is a group of young women for whom the risk of sexual victimization is a reality, generalization should be limited. In addition, we relied on cross-sectional data based on retrospective recall and self-report. Thus, although we assume that risky sexual behavior was the linking factor, we do not know which came first, the risky sexual behavior or the sexual victimization. Further research will be necessary to determine their time-ordered relations. We also examined only self-reported symptoms prior to age 12; we did not assess for use of medications, current symptoms, or have an independent assessment of ADHD diagnoses. Additionally, all our measures of contextual factors were dichotomized due to sample size. For example, further work will be needed to distinguish a stay-at-home parent with no external income from an unemployed parent and examine the nature of supervision that youth receive. Not controlling for other forms of childhood trauma is another limitation. It is possible that the women in our study experienced other forms of trauma not assessed in this study that could be associated with ADHD symptoms. However, even if that is the case, our results emphasize the value of focusing on mechanisms, such as those associated with ADHD symptoms, rather than specific childhood experiences that may account for increased risk of sexual victimization in adolescence. Given the unique contributions of these findings, we believe that the strengths of current study outweigh these limitations. The findings, however, must be interpreted within the context of these limitations.

\section{CONCLUSION}

In sum, a picture emerges that suggests that ADHD symptoms increase the likelihood of engaging in risky sexual behavior, a relation previously established in the literature, as well as the risk for sexual victimization, a new finding revealed by the present research. Furthermore, ADHD symptoms also uniquely increase the risk of sexual victimization. It is likely that what appears to be a direct association in the present data may be accounted for by other risky behaviors not assessed in the present study, such as alcohol and/or drug use. By excluding from the analyses young women with a childhood history of sexual abuse, we have identified a new group at risk for adolescent sexual victimization. Behavioral impulsivity and inattention may be important mechanisms that influence sexual victimization. Such findings have important implications for rape prevention education and intervention. Many programs are either specifically targeted at populations with histories of childhood sexual abuse or are universal programs aimed at all young women. By focusing attention more fully on mechanisms we may be able to develop programs that support women by increasing their capacity to self-regulate. Such findings may be incorporated into programs for youth with ADHD and their parents.

\section{REFERENCES}

Acock, A. (2005). Working with missing values. Journal of Marriage and Family, 67(4), 10121028. 
Adler, N. E., Epel, E. S., Castellazzo, G., \& Ickovics, J. R. (2000). Relationship of subjective and objective social status with psychological and physiological functioning: preliminary data in healthy White women. Health Psychology, 19(6), 586-592.

American Psychiatric Association. (2000). Diagnostic and statistical manual of mental disorders (Revised) (4th ed.). Washington: American Psychiatric Publications.

Arbuckle, J. L. (2011). Amos (Version 20.0). Chicago: IBM SPSS.

Barkley, R. A., \& Murphy, K. R. (1998). Attention-deficit hyperactivity disorder: A clinical workbook. New York: Guilford.

Briscoe-Smith, A. M., \& Hinshaw, S. P. (2006). Linkages between child abuse and attentiondeficit/hyperactivity disorder in girls: behavioral and social correlates. Child Abuse \& Neglect, 30(11), 1239-1255.

Byrne, B. M. (2001). Structural equation modeling with AMOS: Basic concepts, applications, and programming. Mahwah: Erlbaum.

Chu, A. T., Pineda, A. S., DePrince, A. P., \& Freyd, J. J. (2011). Vulnerability and protective factors for child abuse and maltreatment. In J. White, M. Koss, \& A. Kazdin (Eds.), Violence against women and children, Vol 1: Mapping the terrain (pp. 55-75). Washington: American Psychological Association.

Claes, M., Lacourse, E., Ercolani, A. P., Pierro, A., Leone, L., \& Presaghi, F. (2005). Parenting, peer orientation, drug use, and antisocial behavior in late adolescence: a cross-national study. Journal of Youth and Adolescence, 34(5), 401-411.

Crockett, L. J., Raffaelli, M., \& Moilanen, K. L. (2003). Adolescent sexuality: Behavior and meaning. In M. D. Berzonsky \& G. R. Adams (Eds.), Blackwell handbook of adolescence (pp. 371-392). Malden: Blackwell.

Cuffe, S. P., Moore, C. G., \& McKeown, R. (2005). Prevalence and correlates of ADHD symptoms in the National Health Interview Survey. Journal of Attention Disorders, 9(4), 392-401.

DuPaul, G. J., Power, T. J., Anastopoulos, A. D., \& Reid, R. (1998). ADHD rating scale-IV: Checklists, norms, and clinical interpretation. New York: Guilford.

Evans, G. W., \& Rosenbaum, J. (2008). Self-regulation and achievement-income gap. Early Childhood Research Quarterly, 23(4), 504-514.

Fargo, J. D. (2009). Pathways to adult sexual revictimization: direct and indirect behavioral risk factors across the lifespan. Journal of Interpersonal Violence, 24(11), 1771-1791. 
Fergus, S., Lewis, M. A., Darbes, L. A., \& Kral, A. H. (2009). Social support moderates the relationship between gay community integration and sexual risk behavior among gay male couples. Health Education \& Behavior, 36(5), 846-859.

Flory, K., Molina, B. S. G., Pelham, W. E., Gnagy, E., \& Smith, B. (2006). Childhood ADHD predicts risky sexual behavior in young adulthood. Journal of Clinical Child and Adolescent Psychology, 35(4), 571-577.

Flouri, E., \& Kallis, C. (2011). Adverse life events and mental health in middle adolescence. Journal of Adolescence, 34(2), 371-377.

Fulton, E., \& Turner, L. A. (2008). Students' academic motivation: relations with parental warmth, autonomy granting, and supervision. Educational Psychology, 28(5), 521-534.

Gibbs, J. T. (1998). High-risk behaviors in Black youth: Conceptual and methodological issues in research. In V. C. McLoyd \& L. Steinberg (Eds.), Studying minority adolescents (pp. 55-86). Mahwah: Erlbaum.

Gidycz, C. A., McNamara, J. R., \& Edwards, K. M. (2006). Women’s risk perception and sexual victimization: a review of the literature. Aggression and Violent Behavior, 11(5), 441456.

Halpern, C. T., Spriggs, A. L., Martin, S. L., \& Kupper, L. (2009). Patterns of intimate partner violence victimization from adolescence to young adulthood in a nationally representative sample. Journal of Adolescent Health, 45(5), 508-516.

Hedtke, K. A., Ruggiero, K. J., Fitzgerald, M. M., Zinzow, H. M., Saunders, B. E., Resnick, H., \& Kilpatrick, D. G. (2008). A longitudinal investigation of interpersonal violence in relation to mental health and substance use. Journal of Consulting and Clinical Psychology, 76(4), 633-647.

Humphrey, J. A., \& White, J. W. (2000). Women's vulnerability to sexual assault from adolescence to young adulthood. Journal of Adolescent Health, 27(6), 419-424.

IBM Corp. (2011). SPSS Statistics Base (Version 20.0). Chicago: IBM SPSS.

Koss, M. P., Gidycz, C. A., \& Wisniewski, N. (1987). The scope of rape: incidence and prevalence of sexual aggression and victimization in a national sample of higher education students. Journal of Consulting \& Clinical Psychology, 55(2), 162-170.

Koss, M. P., Abbey, A., Campbell, R., Cook, S., Norris, J., Testa, M., et al. (2007). Revising the SES: a collaborative process to improve assessment of sexual aggression and victimization. Psychology of Women Quarterly, 31(4), 357-370. 
Kosson, D. S., Kelly, J. C., \& White, J. W. (1997). Psychopathy-related traits predict selfreported sexual aggression among college men. Journal of Interpersonal Violence, 12(2), 241-254.

LaVeist, T. A., Thorpe, R. J., Mance, G. A., \& Jackson, J. (2007). Overcoming confounding of race with socio-economic status and segregation to explore race disparities in smoking. Addiction, 102(Suppl2), 65-70.

Lonsway, K. A. (1996). Preventing acquaintance rape through education: what do we know? Psychology of Women Quarterly, 20(2), 229-265.

Marcovitch, S., Leigh, J., Calkins, S. D., Leerks, E. M., O’Brien, M., \& Nayena Blankson, A. (2010). Moderate vagal withdrawal in 3.5-year-old children is associated with optimal performance on executive function tasks. Developmental Psychobiology, 52(6), 603-608.

Metzler, C. W., Noell, J., Biglan, A., Ary, D., \& Smolkowski, K. (1994). The social context for risky sexual behavior among adolescents. Journal of Behavioral Medicine, 17(4), 419438.

Monuteaux, M. C., Farone, S. V., Gross, L. M., \& Biederman, J. (2007). Predictors, clinical characteristics, and outcome of conduct disorder in girls with attentiondeficit/hyperactivity disorder: a longitudinal study. Psychological Medicine: A Journal of Research in Psychiatry and the Allied Sciences, 37(12), 1731-1741.

Murray, J., \& Farrington, D. P. (2010). Risk factors for conduct disorder and delinquency: key findings from longitudinal studies. The Canadian Journal of Psychiatry, 55(10), 633642.

Noll, J. G., Trickett, P. K., \& Putnam, F. W. (2003). A prospective investigation of the impact of childhood sexual abuse on the development of sexuality. Journal of Consulting and Clinical Psychology, 71(3), 575-586.

Nurius, P. S., \& Norris, J. (1995). A cognitive ecological model of women’s response to male sexual coercion in dating. Journal of Psychology \& Human Sexuality, 8(1-2), 117-139.

Repetti, R. L., Taylor, S. E., \& Seeman, T. E. (2002). Risky families: family social environments and the mental and physical health of offspring. Psychological Bulletin, 128(2), 330-366.

Roosa, M. W., Tein, J. Y., Reinholtz, C., \& Angelini, P. (1997). The relationship of childhood sexual abuse to teenage pregnancy. Journal of Marriage and the Family, 59(1), 119-130.

Rydell, A. (2010). Family factors and children's disruptive behaviour: an investigation of links between demographic characteristics, negative life events and symptoms of ODD and ADHD. Social Psychiatry and Psychiatric Epidemiology, 45(2), 233-244. 
Slashinski, M. J., Coker, A. L., \& Davis, K. E. (2003). Physical aggression, forced sex, and stalking victimization by a dating partner: an analysis of the National Violence against Women Survey. Violence and Victims, 18(6), 595-617.

Smith, P. H., White, J. W., \& Holland, L. J. (2003). A longitudinal perspective on dating violence among adolescent and college-age women. Journal of American Public Health Association, 93(7), 1104-1109.

Soet, J. E., Dudley, W. N., \& Dilorio, C. (1999). The effects of ethnicity and perceived power on women's sexual behavior. Psychology of Women Quarterly, 23(4), 707-723.

Steinberg, L. (2010). A behavioral scientist looks at the science of adolescent brain development. Brain and Cognition, 72(1), 160-174.

Steinberg, L., Dahl, R., Keating, D., Kupfer, D. J., Masten, A. S., \& Pine, D. S. (2006). The study of developmental psychopathology in adolescence: Integrating affective neuroscience with the study of context. In D. Cicchetti \& D. Cohen (Eds.), Developmental psychopathology, Vol 2: Developmental neuroscience (2nd ed., pp. 710741). Hoboken: Wiley.

Testa, M., VanZile-Tamsen, C., Livingston, J. A., \& Koss, M. P. (2004). Assessing women’s experiences of sexual aggression using the sexual experiences survey: evidence for validity and implications for research. Psychology of Women Quarterly, 28(3), 256-265.

Tjaden, P., \& Thoennes, N. (2000). Prevalence and consequences of male-to-female and femaleto-male intimate partner violence as measured by the National Violence against Women Survey. Violence against Women, 6(2), 142-161.

U.S. Department of Health and Human Services (2000). Healthy people 2010: Understanding and improving health. Retrieved February 25, 2011, 2011, from http://www.health.gov/healthypeople/url/

Ullman, S. E., \& Najdowski, C. J. (2011). Vulnerability and protective factors for sexual assault. In J. White, M. Koss, \& A. Kazdin (Eds.), Violence against women and children, Vol 1: Mapping the terrain (pp. 151-172). Washington: American Psychological Association.

Vicary, J. R., Klingaman, L. R., \& Harkness, W. L. (1995). Risk factors associated with date rape and sexual assault of adolescent girls. Journal of Adolescence, 18(3), 289-306.

Waite, R. (2007). Women and attention deficit disorders: a great burden overlooked. Journal of the American Academy of Nurse Practitioners, 19(3), 116-125.

Waite, R. (2010). Women with ADHD: it is an explanation, not the excuse du jour. Perspectives in Psychiatric Care, 46(3), 182-196. 
Watts-English, T., Fortson, B. L., Gibler, N., Hooper, S. R., \& DeBellis, M. D. (2006). The psychobiology of maltreatment in childhood. Journal of Social Issues, 62(4), 717-736.

Whitbeck, L. B., Hoyt, D. R., Yoder, K. A., Cauce, A. M., \& Paradise, M. J. (2001). Deviant behavior and victimization among homeless and runaway adolescents. Journal of Interpersonal Violence, 16(11), 1175-1204.

Winters, K. C., Botzet, A. M., Fahnhorst, T., Baumel, L., \& Lee, S. (2009). Impulsivity and its relationship to risky sexual behaviors and drug use. Journal of Child \& Adolescent Substance Use, 18(1), 43-56.

Young, B. J., \& Furman, W. (2009). Interpersonal factors in the risk for sexual victimization and its recurrence during adolescence. Journal of Youth Adolescence, 37(3), 297-309. 